\title{
EFFECT OF DELAMINATION ON THE FATIGUE LIFE OF GFRP: A THERMOGRAPHIC AND NUMERICAL STUDY
}

\author{
Chiara COLOMBO ${ }^{1 *}$, Dhawale Trunal BHUJANGRAO ${ }^{1}$, \\ Flavia LIBONATI ${ }^{1}$, Laura VERGANI ${ }^{1}$
}

\author{
${ }^{1}$ Politecnico di Milano, Department of Mechanical Engineering \\ Via La Masa 1, 20156 Milano, Italy \\ * Corresponding author: chiara.colombo@polimi.it
}




\begin{abstract}
:
Delamination is the major failure mechanism in composite laminates and eventually leads to material failure. An early-detection and a better understanding of this phenomenon, through non-destructive assessment, can provide a proper in situ repair and allow a better evaluation of its effects on residual strength of lightweight structural components. Here we adopt a joint numerical-experimental approach to study the effect of delamination on the fatigue life of glass/epoxy composites. To identify and monitor the evolution of the delamination during loading, we carried out stepwise cyclic tests coupled with IR-thermography on both undamaged and artificially-damaged samples. The outcome of the tests shows that IRthermography is able to identify a threshold stress, named damage stress $\sigma_{\mathrm{D}}$, which is correlated to the damage initiation and the fatigue performance of the composite. Additionally, we performed FE-simulations, implementing the delamination by cohesive elements. Such models, calibrated on the basis of the experimental fatigue results, can provide a tool to assess the effect of parameters, such as the delamination size and location, and composite stacking sequence, on the residual strength and fatigue life of the composite material.
\end{abstract}

Keywords: GFRP-composites; delamination; IR-thermography; cohesive elements. 


\section{1) Introduction}

Composite materials can present different types of defects or damages, created by the manufacturing process or generated during service, in particular in presence of fatigue loading. Residual fatigue life, stiffness and strength are directly related to the presence of such defects. To follow a defect tolerant approach both in the design stage and in the residual life estimation, it is important to have information about the fatigue behaviour of the material in presence of defects. Among the defects occurring in fibre reinforced composite materials, the delamination is one of the most common and dangerous from the structural point of view, as it significantly reduces the inter-laminar strength and frequently leads to premature initiation of failure [1]. For this reason, the problem of delamination, has been extensively studied in the literature, from experimental [2], analytical [3] and numerical [4] points of view. Regarding the experimental viewpoint, many non-destructive techniques have been developed in the past decades, with the aim of detecting the presence of delamination in composite materials and monitoring its evolution. To cite a few: light microscopy, acoustic emission, ultrasonic, radiographic and tap testing.

In the present paper, we focus on the use of Infra-Red (IR) thermography, a well-known technique that supplies full-field surface temperature of bodies without direct contact. It is generally much more rapid than alternative techniques, e.g. conventional ultrasounds [5] and tap testing [6]. IR-thermography has several advantages, such as fast inspection rate, no contact, safety (no harmful radiation involved) and results relatively easy to interpret [7]. On the contrary, the main drawbacks and limitations of this experimental techniques are: i) the effects of thermal losses perturbing the thermal contrast, ii) the cost of the equipment (IRcamera and related software), and iii) the ability to inspect only a limited thickness of material under the surface (indeed, thermography could be defined as a "boundary" technique) [7]. Nevertheless, IR-thermography is widely adopted in diverse fields, not only structural $[8,9]$, and applied to both homogeneous and composite materials [10]. Moreover, the recent developments of IR imaging systems, making them portable and easy to be adapted to various geometries, allow them to be used for in situ inspections [11].

IR-thermography can be applied into different modes. Among them, lock-in thermography $[12,13]$ is one of the most used. It considers the analysis of thermal waves occurring into a body undergoing cyclic loading. The resulting oscillating temperature field or thermal infrared emissions, in stationary regime, can be recorded remotely through an IR-camera. Comparing 
the thermographic signal with the loading one and using a suitable filtering, based on the Fast Fourier Transform and a dedicated algorithm, it is possible to decompose the thermographic signal in two parts: 1) one having the same frequency of the mechanical input (first order harmonic), and 2) the other having a different frequency, typically higher (second order harmonic). The first order harmonic is related to the thermo-elastic signals, whereas the second order one is related to the dissipative signals. First and second harmonic signals are processed in terms of amplitude (A) and phase ( $\varphi$ ) of the thermal wave, respectively [14].

The assessment of structural integrity of components made of composite materials is a fundamental topic. For this reason, in literature several works focused on the application of IRthermography to early-detect damage in composite materials. Thermo-elastic analyses, based on first order harmonic, were performed in [15]. More recently, the assessment of damage in composite materials has been achieved by thermographic analyses based on dissipative energy related to second order harmonic [16]. In particular, in [17] this analysis was applied to basalt reinforced composites to detect the damage initiation. Moreover, the authors of [18] proposed the analysis of the second harmonic as a promising approach to detect the load amplitude threshold at which dissipative damage phenomena start occurring in a natural flax fibre reinforced epoxy polymer composite. This technique was also recently extended to the damage detection in hybrid metal-polymer-metal sandwich panels [19].

Besides the above described experimental techniques, the scientific literature also developed some numerical methods to be used in a damage tolerant approach for composites. One of the most adopted method to analyse the stress state and simulate the delamination, is the Cohesive Zone Modelling (CZM), based on the Finite Element Analysis (FEA). CZM is a phenomenological model, based on the definition of the failure energy that is required by the crack or delamination to propagate. CZM requires as input the Traction-Separation Law (TSL) that describes the mechanical behaviour of the cohesive elements, which are zero thickness elements embedded in the plane of crack propagation, at the interface between two laminae. In the literature, CZM is largely used for the analysis of delamination in composite materials, because of its simplicity and versatility in the prediction of both the onset and the propagation. Saeedifar et al. [20] and Haselbach et al. [21] have shown that the CZM technique exhibits good performance in simulating crack initiation and delamination crack length in laminated composite structures. Most of the works dealing with delamination are focused on mode I loading, e.g. Double Cantilever Beam (DCB) in opening mode. For instance, a probabilistic CZM was developed by Shanmugam et al. [22] to capture steady-state energy release rate variations in DCB specimens with delamination. However, literature presents also valid works 
on the numerical study of delamination in mixed-mode loading [23] to successfully predict delamination failures in the pre-defined locations. Although traditional CZM were focused on static loading, as in [21], these simulations have recently been extended also to fatigue loading. For instance, Wang and $\mathrm{Xu}$ [24] used cohesive elements to simulate propagation of a delamination, including descriptions of both propagation direction and length under high-cycle fatigue loading. Jimenez and Duddu [25] showed a parametric cohesive study for high-cycle fatigue delamination in relation to constituent cohesive strength and stiffness. Kakei et al. [26] presented a numerical and experimental study on the delamination effect in a carbon fibre reinforced composite, considering a symmetric through-thickness configuration with two delaminated layers.

The present paper represents an extension of previous experimental works, that presented results from static and fatigue tests on undamaged specimens [27] and on intentionally predelaminated specimens [28], made of Glass Fibre Reinforced Plastics (GFRP). Through the thermographic technique, the authors identified a stress corresponding to the damage initiation, named damage stress $\sigma_{\mathrm{D}}$. The latter has shown to be close to the high cycle fatigue strength determined by a fatigue experimental campaign, suggesting that below this stress amplitude a change in failure mechanisms occurs and the delamination is not likely to be present. Here we provide a further experimental investigation including fatigue testing performed on GFRP predelaminated samples, with an artificially-induced delamination, in a plane close to the upper surface. We applied IR-thermography to determine the damage stress in case of non-symmetric delamination and compared the results with the previous one presented in [28].

The novelty of this study consists in the addition of a numerical procedure, based on CZM of delamination, aimed at providing a new tool for the delamination assessment and the residual fatigue life estimation. This numerical procedure is based on Abaqus and Autodesk Helius software, following the approach proposed in [26]. The numerical models, calibrated on previous experiments, allow one to determine the evolution of delamination damage in the samples subjected to fatigue loading. Moreover, the modelling framework is also used to perform a sensitivity analysis, evidencing the main factors affecting the fatigue performances of delaminated samples. 


\section{2) Methods}

\section{1) Materials}

Object of this research is a GFRP composite, made of non-crimp glass fabric $\left(600 \mathrm{~g} / \mathrm{m}^{2}\right)$ and epoxy resin (Epikote Resin L1100, with $20 \%$ of 294 and 80\% of 295 Epikure ${ }^{\circledR}$ curing agents by Hexion). For this work we consider three laminate plates, from now on called $S, T$, and $U$, having a nominal thickness of $4.4 \mathrm{~mm}$ and the following stacking sequence of $[ \pm 45]_{10}$.

- $S$ indicates a standard laminate plate with no intended defects and $50 \%$ vol. fibres. The samples obtained from this plate, here identified with the letter $\mathrm{S}$, have been characterized in a previous study [27] and showed the following properties: UTS $=142 \mathrm{MPa}, \mathrm{E}=9550$ $\mathrm{MPa}$.

- $T$ indicates a laminate having 55\% vol. fibres and a Teflon (PTFE) tape, $20 \mathrm{~mm}$ width and $0.1 \mathrm{~mm}$ thick, placed in the middle of the lay-up, in between the $5^{\text {th }}$ and the $6^{\text {th }}$ layer. The samples obtained from this plate, here identified with the letter $\mathrm{T}$, have been characterized in a previous study [28] and showed the following properties: UTS $=155 \mathrm{MPa}, \mathrm{E}=10600$ $\mathrm{MPa}$.

- $U$ indicates a laminate having 55\% vol. fibres and a Teflon (PTFE) tape, $20 \mathrm{~mm}$ width and $0.1 \mathrm{~mm}$ thick. The Teflon tape, aimed at simulating a delamination close to the upper surface, is placed between the $8^{\text {th }}$ and the $9^{\text {th }}$ layer. The specimens cut from this delaminated plate, here identified with the letter $U$, have the following properties UTS $=155 \mathrm{MPa}, \mathrm{E}=$ $10600 \mathrm{MPa}$.

Figure 1.a shows the dimensions of the sample series $S, T$ and $U$, according to the ASTM D 3039. Adhesively bonded tabs, $30 \mathrm{~mm}$ long, are glued to the specimen edges, to avoid stress concentration in the grip area. Being the laminates semi-transparent, the white-coloured Teflon paper is clearly visible by simple backlight (Figure 1.b), making it possible to check the presence/absence of delamination in the composite. Figure 1.b shows $U$ specimens, together with $S$ and $T$ specimens used in [27,28].

Figure 1: a) Dimensions of the delaminated specimens ( $\mathrm{mm}): \mathrm{t}$ is the specimen thickness; $\mathrm{d}$ is the delamination size; $z_{D}$ is the through-thickness location of the delamination, represented by means of a blue line; b) GFRP specimens: $S$-type represents the standard or undamaged specimen, $T$-type the sample with a delamination placed in the middle of the lay-up, and $U$-type the sample with delamination placed close to the upper layer. 


\section{2) Experimental testing}

Experimental tests are performed using an MTS Landmark servo-hydraulic universal testing machine endowed with a $100 \mathrm{kN}$ load cell. The specimen is fastened into the machine with grips at the ends. Figure 2 shows the scheme of the experimental setup. All the tests are thermally monitored by means of an IR-thermal camera (FLIR, model: Titanium SC7000), which is placed in front of the specimens at about $200 \mathrm{~mm}$ from the surface to be observed. The scanned region corresponds to the central part of the specimen, since extremities can be affected by heat transfer from grips.

Figure 2: Scheme of the experimental setup and devices: sample placed into a universal servo-hydraulic testing machine and surface observed through an IR-thermal camera.

With this testing setup, we can simultaneously detect the mechanical and thermal behaviour of the sample surface. During the experimental tests, the thermal camera is connected to a laptop and set to record not only matrices of surface temperatures, but also a reference signal from the load cell of the testing machine. The two recorded signals, mechanical and thermal, are synchronized by means of the lock-in module. In case of cyclic load applied to the specimen, e.g. during stepwise tests, the force signal from the load cell is used into the lock-in module to measure more precisely the cyclic temperature change, in terms of phase and amplitude, with respect to the modulated input load signal.

Results of static, fatigue, and stepwise tests on $S$ and $T$ specimens were previously discussed in [28], underlining that fatigue tests are deeply influenced by the presence of the delamination, contrary to static tests. For this reason, in the present work, besides a static characterization, we also performed stepwise tests on $U$ specimens. Table 1 summarizes the total number of specimens tested, including those of the previous study [28].

Table 1: Number of experimental tests performed for each sample type. $S$ series represents the standard or undamaged specimens, $T$ series represents the samples with a delamination placed in the middle of the lay-up, and $U$ series represents the samples with a delamination placed close to the upper layer.

The stepwise tests consist in the application of consecutive and increasing loading blocks to the samples, where the stress amplitude is constant within each loading block, lasting $5 \times 10^{3}$ cycles. The load is stepwise increased by $2 \mathrm{MPa}$, with maximum stresses ranging from $22 \mathrm{MPa}$ up to the specimen failure (maximum applied stress: $52 \mathrm{MPa}$ ); the maximum number of applied loading blocks is 16 . These tests are performed in load control, at constant stress ratio equal to 
0.1 and a load frequency of $20 \mathrm{~Hz}$. This load frequency value was selected in order to have adiabatic condition of the specimen, also in accordance with [29]. Thermal data acquisition frequency is set to $25 \mathrm{~Hz}$.

During the stepwise tests, after a calibration based on a non-uniformity correction (NUC) [30], the thermal camera captures the temperature variation of the specimen surface $\Delta \mathrm{T}$. By means of the lock-in module, these data can be processed to detect three different contributions $[13,31]$ :

$$
\Delta T=\Delta T_{C}+\Delta T_{D}+\Delta T_{E}
$$

where:

- $\Delta T_{C}$ is the temperature variation caused by external events, such as room temperature variation, air flow, etc. and by non-adiabatic conditions. This term should be limited during testing: for this reason, we carried out stepwise tests into a conditioned room, in controlled temperature condition;

- $\Delta T_{D}$ is the temperature variation caused by dissipative irreversible phenomena. This signal is out of phase with respect to the load signal. The amount of dissipated heat is proportional to the damage and the local intensities, the spatial distribution, the location, the chronology and duration of emission, is peculiar to the damage events that cause it [32];

- $\Delta T_{E}$ is the temperature variation due to the thermo-elastic effect, under adiabatic conditions. This signal is in counterphase with respect to the reference load signal, according to the well-known equation of thermo-elasticity, that for plane-stress orthotropic materials is simplified as follows [29]:

$$
\Delta T_{E}=-\frac{T_{0}}{\rho C_{p}}\left(\alpha_{11} \Delta \sigma_{11}+\alpha_{22} \Delta \sigma_{22}\right)
$$

where: $\rho$ is the mass density; $C_{p}$ is the specific heat at constant pressure; $T_{0}$ is the absolute temperature of the solid at the surface; $\alpha_{11}$ and $\alpha_{22}$ are the coefficients of thermal expansion along the principal in-plane material directions; $\sigma_{11}$ and $\sigma_{22}$ are the stresses in the principal in-plane directions.

The thermo-mechanical answer of composites under stepwise loading is analysed to detect the variation of the thermal signal corresponding to the initiation of the material damage. This value is correlated with a stress called damage stress, $\sigma_{\mathrm{D}}$. We used three different methods: 1 ) the slope method, 2), the D-Mode analysis, and 3) the E-Mode analysis. 
The first method, aka slope method, was first introduced for homogeneous materials by [33]. According to this method, the slope $\Delta \mathrm{T} / \Delta \mathrm{N}$ (i.e. the temperature variation with respect to the number of cycles) shows a bi-linear trend, when plotted as a function of the maximum applied stress, $\sigma_{\max }$, and the breakup point identifies the damage stress, $\sigma_{\mathrm{D}}$.

The second method is based on the dissipated temperature $\Delta \mathrm{T}_{\mathrm{D}}$. For the analysis of both the dissipated and the thermoelastic signals we used the software ALTAIR-LI by FLIR. Regarding the dissipated energy, connected to the secondary harmonic with respect to the reference load signal, the software returns the values of the signal amplitude for each loading block, commercially named D-mode. The evaluation of the D-mode requires a dedicated algorithm, which separates the dissipative energy from the thermo-elastic source and filters signals based on Fourier Transform analysis. D-mode evaluates this dissipated energy extracting non-linear coupled thermo-mechanical effects during cycling. Through this method, we can associate the dissipative energy production with the material damage onset, related to the beginning of irreversible loss of energy.

The third method is based on the thermo-elastic temperature variation $\Delta \mathrm{T}_{\mathrm{E}}$ (Eq. 2). The thermoelastic signal has the same frequency of the reference one, and, in case of fully elastic behaviour, this is the unique signal. The used software returns the thermo-elastic signal value, commercially called E-Mode, in terms of amplitude and phase with respect to the load signal.

\section{3) Finite element simulations}

The numerical models are created with the software Abaqus (v. 6.13) and Helius. They are modelled using 3D solid elements (C3D8I) for the regions of the composite material, and by 3D cohesive elements (COH3D8) in front of the two sides of the delamination, as in [26]. All the models simulate the central part of the specimens (Figure 3.a), neglecting the grips, as the failure always occurred experimentally in the central region of the specimens. Specimens are loaded at one end in longitudinal direction and fixed at the other end.

Figure 3: a) Example of mesh generated for the $T$ specimens; b) Cohesive parameters of the triangular TSL: $\mathrm{T}_{\mathrm{t}}$ maximum traction for tensile load; $\delta_{0}$ and $\delta_{\mathrm{F}}$ initial and final separation; $\mathrm{G}_{\mathrm{C}}$ fracture energy; $\mathrm{K}$ initial stiffness.

Three finite element (FE) models are developed, to simulate the three different specimen types, $S, T$, and $U$. 
The first FE model simulates $S$ specimens and is used to calibrate the input parameters of the laminate material (i.e. stiffness and strengths of the laminas) on the basis of the experimental $\mathrm{S}-\mathrm{N}$ curves. To set these numerical inputs of the composite, we cross-checked the estimation of these mechanical properties using the software Helius Composite and the database MechGcomp [34]. Table 2.a summarizes the values of the mechanical properties used in the numerical simulations of the composite laminae. Each 3D composite solid element was defined by the related stacking sequence and the mechanical properties of the laminae in the local reference frame.

Table 2: a) Mechanical properties of the composite lamina; 1-2 is the local in-plane reference frame of the composite lamina; axis 3 is the trough-thickness direction; b) Cohesive properties.

The numerical simulation of the fatigue life was performed by the software Abaqus combined with the software Autodesk ${ }^{\circledR}$ Helius PFA [35], which allows defining a base fatigue cycle to be repeated within the analysis. This fatigue cycling is the experimental one, undergone by each specimen [28], i.e. at given $\sigma_{\max }$ and with stress ratio $\mathrm{R}=0.1$ and frequency $20 \mathrm{~Hz}$. The used Autodesk ${ }^{\circledR}$ software, through a specific Plug-in for Abaqus, creates a UMAT subroutine to calculate output State Defined Variables or SDV for the composite materials [35]. Abaqus stores these state variables during the analysis, at each individual integration point within the finite elements. One of these state variables, SDV2, evaluates the number of cycles to failure $\mathrm{N}_{\mathrm{f}}$.

The second FE model simulates the delaminated $T$ specimens. With the aim of including the delamination, the central part of the model is divided in four regions: two solid regions corresponding to the upper and lower non-delaminated parts, and two cohesive zero-thickness layers in front of the delamination. Figure 3.a shows the geometry of the delaminated $T$ specimen. The mechanical properties of the solid elements are calculated from the first simulation, see Table 2.a. For the cohesive elements we selected a triangular tractionseparation law (TSL). Figure 3.b schematizes the characteristic parameters in terms of displacement and strength; their values are given in Table 2.b. These values of cohesive stress and displacements are calibrated from a trial $\&$ error procedure. Starting from literature TSL values [36], we iterated the values of the cohesive parameters until the S-N curve numerically estimated is overlapped with the experimental results of the $T$ specimens [28]. The Helius plugin for Abaqus creates a new UMAT subroutine, with nine State Defined Variables, SDV $_{\text {coh, }}$ for this specific simulation with cohesive elements [35]. Among these variables we can cite: 
$\mathrm{SDV} 2_{\text {coh }}$ indicating if the damage initiation criterion has been satisfied, SDV $6_{\text {coh }}$ estimating the cumulated damage, $\mathrm{SDV}_{\mathrm{coh}}$ is the work done in the normal loading mode or mode I (local zdirection), $\mathrm{SDV}_{\text {coh }}$ stores the work done in the first shear loading mode or mode II (local xdirection), SDV9 $9_{\text {coh }}$ stores the work done in the second shear loading mode or mode III (local y-direction). The fatigue criterion implemented in Helius PFA is the Multicontinuum Theory, MCT [37].

The third simulation is dedicated to $U$ specimens. The model is created similarly with respect to the previous one, implementing the mechanical properties of the materials within the plugin in Abaqus.

\section{4) Sensitivity analysis}

To further investigate the effect of delamination on the laminated composite, we exploited our numerical tool to perform a sensitivity analysis. Indeed, the validated numerical model can be used as a design tool to elucidate the effect of different parameters: for instance, it could be useful for the optimization of the structures under loads with variable direction and for the estimation of the residual fatigue life of damaged structures. With this aim, we selected some parameters whose variation can be of an interest to the structural designer. More in details, we can use the cohesive model to estimate how the fatigue life is affected by: 1) the throughthickness location of the composite delamination, 2) the lay-up orientation of the composite, 3) the delamination size. Other extrapolations of the FE model for the fatigue life estimation can be possible, for instance changing the matrix or fibre types. However, such extrapolations require a tailored calibration of the mechanical properties of the composite and of the cohesive elements to be embedded into the analysis.

The effect of location has been investigated by placing the delamination in different positions with respect to the laminate thickness, in particular at a distance $z_{D}=2.64 \mathrm{~mm}$ (see Figure 1) from the external surface (between $6^{\text {th }}$ and $7^{\text {th }}$ layer $), z_{D}=3.08 \mathrm{~mm}\left(7^{\text {th }}\right.$ and $8^{\text {th }}$ layer $), z_{D}=3.52$ $\mathrm{mm}\left(8^{\text {th }} \& 9^{\text {th }}\right.$ layer $)$, and $\mathrm{z}_{\mathrm{D}}=3.96 \mathrm{~mm}\left(9^{\text {th }} \& 10^{\text {th }}\right.$ layer $)$. The effect of fibre orientation has simulated by modelling three configurations: $[0,90],\left[ \pm 45^{\circ}\right]$, and $[0,0,0, \pm 45,0]$. Finally, the effect of the delamination size is analysed by developing models with different $d$ values with respect to Figure 1: $d=10 \mathrm{~mm}$ and $d=30 \mathrm{~mm}$. 


\section{3) Results}

\section{1) Dynamic methods to evaluate the damage stress through IR-thermography}

Figure 4 shows the trends of the curves obtained by the three different approaches. Every curve corresponds to one sample, being the curves obtained by different samples similar and reproducible.

Figure 4: Curves for the thermographic determination of the damage stress $\sigma_{\mathrm{D}}$ in $S, T$ and $U$ specimens, by using three different methods: a) $\Delta \mathrm{T} / \Delta \mathrm{N}$ vs $\sigma_{\max } / \mathrm{UTS}(\%)$, b) D-mode vs $\sigma_{\max } / \mathrm{UTS}(\%)$, c) E-mode vs $\sigma_{\max } / \mathrm{UTS}(\%)$.

Figure 4.a shows the $\Delta \mathrm{T} / \Delta \mathrm{N}$ vs $\sigma_{\max } / \mathrm{UTS}$ trends for all the samples series $S, T$ and $U$. In all the cases, according to the slope method, a bi-linear trend is observed. The procedure to estimate the slope and the damage stress is automatized into a Matlab script, by considering almost linear trends in each block of cycles. The $S$ undamaged specimens, without pre-delamination, have a higher value of $\sigma_{\mathrm{D}}$, with respect to the $T$ and $U$ specimens, which instead show an almost overlapped trend. This indicates that the delamination, independently on its location within the laminate thickness, has influence on the fatigue performance, reducing the damage stress level. Figure 4.b shows the bi-linear trends of D-mode as a function of $\sigma_{\max } / \mathrm{UTS}$ for the three specimens, according to the second method. At the beginning of the test, the trend is almost flat, and the dissipated energy is near to zero. With the increase of the stress amplitude, on the contrary, a progressive raise in the dissipated energy occurs. As we did for the slope method, the trend of experimental D-mode data is interpolated by two straight lines, and the intercept identifies a second estimation of damage stress, $\sigma_{\mathrm{D}}$. The secondary slope of the $U$ specimens is steeper than the $T$ specimens, while the $S$ specimens experience the flattest secondary trend. This can indicate that the delamination placed close to the specimen surface is more severe than the delamination placed at the laminate midplane, in terms of fatigue performance.

Figure 4.c shows the trends of the E-mode amplitude values, as a function of $\sigma_{\max } / \mathrm{UTS}$, following the third method. Considerations similar to the D-mode plots can be drawn. The breakup point from the E-mode analysis, as for the previous two methods, is a third estimation of the damage stress $\sigma_{\mathrm{D}}$ and is comparable with the estimations made by the other two methods. 
The three thermographic methods used for thermal data post-processing provide similar $\sigma_{\mathrm{D}}$ values for each specimen type (see Table 3 ). The delaminated specimens show a lower $\sigma_{\mathrm{D}}$ value than the undamaged ones. No remarkable difference can be evidenced between $T$ and $U$ specimens. According to previous experimental observations [14] and [38], the determined damage stress, $\sigma_{\mathrm{D}}$, could be considered as the fatigue strength of the studied composite material.

\section{2) Estimation of crack initiation through thermal camera}

During the stepwise tests, there was no visible crack propagation up to the last loading block, when damage propagation is extremely fast and leads to the complete specimen failure.

Figure 5: Failure of a $U$-specimen after stepwise tests.

The microscopic image of Figure 5 shows a magnification of the delamination region of a Uspecimen after a stepwise test. This figure evidences that only one of the delamination fronts mainly propagates (left side) and, then, tends to separate the 10 layers with multiple interface delaminations. In the central part of the image, the influence of the Teflon layer is visible: the two upper layers are split up with respect to the 8 bottom layers. Finally, on the right side these two portions are gathered together to create the original composite layer. The microscopic analysis showed that the pre-existing delamination activates a preferential path for the crack propagation.

Due to the thermographic monitoring, we did not interrupt tests for microscopic investigation of delamination initiation and propagation. Indeed, stopping the test would have influenced the thermographic setup and measurements. Therefore, to detect the beginning of crack propagation, we analysed the E-mode phase signal and obtained significant information.

Figure 6 shows maps of E-mode phase for a $U$ sample during the last part of the test. Variations in colour correspond to variation in the phase of the thermo-elastic response and indicate the beginning of irreversible damages. The red dotted lines in frames (a)-(d) indicate the original size of the delamination. From frame (b), a phase variation can be detected into the delaminated area and near the bottom left edge of the new damage. During the test, this change in phase progressively extends along the $45^{\circ}$ direction and towards the right side of the specimen (see Frames c, d). At the end of the test, corresponding to frame (d), both the new damage and the 
initial delamination are extremely wide. The maps of Figure 6 identify the damage process region, i.e. where the damage is located and progressively increases.

\footnotetext{
Figure 6: Phase shift of thermoelastic signal during a stepwise test of a U-type specimen. Frames: a) before visible propagation of the delamination; b) damage initiation with estimation of the damage size, c) during damage propagation; d) last step of the test. $\mathrm{N}$ is the corresponding number of cycles; $\mathrm{N}_{\mathrm{f}}$ is the number of cycles corresponding to the specimen failure.
}

Figure 6.b shows that the damage starts propagating from the edge of the delamination, but in the meantime many other local cracks ahead of the delamination are raising, leading to the damage of the whole specimen. From these thermal phase maps, we can identify the pixels corresponding to the damage area during the loading cycles. The delamination grows monotonically with load increasing, as expected, with a reduced rate though. This is likely a result of an increasing number of local cracks occurring in the composite, as shown in Figure 6.b-c-d.

\section{3) FE-simulation of fatigue life}

From the simulations on $S$-type samples, we obtained the $\mathrm{S}-\mathrm{N}_{\mathrm{f}}$ curve shown in Figure 7.a. The figure plots the numerical estimation and the experimental values [28] of the number of cycles to failure $\mathrm{N}_{\mathrm{f}}$ for the $S$ specimens. These data are overlapped, because they were used for the calibration of the composite properties. In the graph, the damage stress estimated by thermography is added as a possible indication of the fatigue strength, i.e. a flat trend of the $\mathrm{S}-\mathrm{N}$ curve at high number of cycles.

Figure 7: Comparison between numerical and experimental [28] $\sigma_{\max } \operatorname{vs} \log \left(\mathrm{N}_{\mathrm{f}}\right)$ plot or S-N curve for: a) $S$ specimens and b) $T$ and $U$ specimens. Runout specimens are identified by arrows.

Figure 7.b shows the S-N curve used for the calibration of the cohesive parameters. Also for this plot, as in Figure 7.a, the $\sigma_{\mathrm{D}} / \mathrm{UTS}$ threshold is added to highlight the fatigue strength of the material in case of a pre-existing delamination. From the FE-analysis, we can also estimate the number of cycles to failure for $U$ specimens. The numerical points corresponding to $U$ specimens are numerical predictions.

The slope of the S-N curve in the finite life region is slightly higher for $U$ than for $T$ specimens; both the slopes for $T$ and $U$ specimens are significantly higher than $S$ specimens, even if the fatigue strength values are similar. This indicates that the presence of delamination generally 
affects the damage propagation speed, reducing the material life, for stress values higher than the damage stress, $\sigma_{\mathrm{D}}$.

Crack initiation and damage parameters can be analysed by the state variables SDV2 $2_{\text {coh }}$ and SDV6 $6_{\text {coh. }}$ Figure 8 compares these variables for $T$ and $U$ specimens. Regarding $T$ specimens, from these fields we can infer that the crack initiated from the delamination front in an almost uniform way. However, in the meantime, other cracks ahead of the delamination front raised and propagated; on the contrary, the main delamination front is arrested. A similar phenomenon occurs for $U$ specimens, where the main delamination initially starts propagating from the lateral edges, and then spreads ahead of the original front. This phenomenon was also observed by thermographic measurements, as discussed in Section 3.2.

Figure 8: State defined variables $\left(\mathrm{SDV}_{\mathrm{coh}}\right)$ into the cohesive layers of $T$ (left) and $U$ (right) specimens, at the end of the analysis. SDV $2_{\text {coh }}$ indicates crack initiation; $\mathrm{SDV}_{\text {coh }}$ indicates the cumulated damage. Both these $\mathrm{SDV}_{\text {coh }}$ range between 0 (no damage) and 1 (full damage).

To better understand this behaviour, we also analysed the trough-thickness displacement (i.e. U3, along z-axis) at the delamination front. Figure 9 shows this displacement field, evidencing a local bending of the upper layer at the delamination front. This local bending may also cause a local increase in stress, thus accelerating the damage propagation for the $U$ specimens.

Figure 9: Displacement field U3 along the trough-thickness direction (z-axis). Values are in mm.

Figure 10 shows the work done for crack propagation in mode I (SDV7 $\left.7_{\mathrm{coh}}\right)$ and mode II $\left(\mathrm{SDV} 8_{\mathrm{coh}}\right)$. These values are higher than mode III $\left(\mathrm{SDV} 9_{\mathrm{coh}}\right)$ for $T$ and especially for $U$ specimens. This suggests that all the delaminated specimens undergo mixed mode loading. However, mode I is the most severe for both the specimen types, since SDV7 $7_{\text {coh }}$ has higher values than the other two state defined variables, i.e. at least double the values of $\mathrm{SDV} 8_{\text {coh }}$ and SDV9 $9_{\text {coh. }}$ Comparing the values reported in Figure 10, it is evident that mode I loading of the delamination is higher for $U$ specimens than $T$ specimens, suggesting local bending of the layers. Therefore, we can observe that the location of the delamination affects the local bending and, thus the local stress state. In other words, non-symmetrical delamination and its further propagation caused a reduction in the laminate bending stiffness. This is an important consideration to deeply understand the failure mode of these specimens under fatigue loading. 
Figure 10: State defined variables $\mathrm{SDV} 7_{\mathrm{coh}}, \mathrm{SDV} 8_{\mathrm{coh}}, \mathrm{SDV} 9_{\text {coh }}$ give the work done in Mode I, Mode II, Mode III respectively: a) $T$ specimen b) $U$ specimen. Magnification at the delamination tips.

In summary, the presence of the delamination seems not to modify the fatigue strength. On the contrary, the crack growth rate is largely affected by this defect and in particular by its location, making the non-symmetrical delamination the most severe.

\section{4) Sensitivity Analysis}

Table 4 summarizes the results of sensitivity analyses, considering three variable parameters, i.e. 1) delamination location through the laminate thickness, 2) lay-up sequence, and 3) delamination size.

Considering the first point, when the delamination moves from the midplane towards the surface of the specimen, it results that the number of cycles to failure decreases up to $40 \%$. Thus, the numerical simulations show a deep influence of the location of the delamination on the fatigue life. The position of the delamination plays an important role for all the applied stresses, that is throughout the finite life region of the composite material. When a delamination is located near the surface, it is more dangerous as a bending phenomenon occurs between the upper and lower compact lamina, and this decreases the fatigue life of the overall structure.

Table 4: Number of cycles to failure $\mathrm{N}_{\mathrm{f}}$, numerically estimated from $\mathrm{SDV} 2_{\text {coh }}$, for different positions of the delamination, stacking sequence and size of the delamination.

Table 4 also shows that the number of cycles to failure varies for different stacking sequences, when a delamination is present at the midplane. The table considers some examples of lay-up: the stacking sequence $[0,90]$ results in $60 \%$ higher fatigue life than the $\left[ \pm 45^{\circ}\right]$ one, selected for the previous analyses. Instead, for the almost longitudinal stacking sequence $[0,0,0, \pm 45,0]$, the simulation results in runout. This shows that the stacking sequence has a large effect on the fatigue life and on the delamination propagation, even in presence of a delamination.

The effect of delamination size, on the contrary, is limited, i.e. different sizes have similar effect on number of cycles to failure. This means that, once the delamination is present in the composite, its effect deeply limits the finite fatigue life, almost independently on its extension. Therefore, we can state that if the energy level for the delamination activation is reached, i.e. applying a load causing stresses higher than the runout stress or $\sigma_{\mathrm{D}}$, the delamination quickly propagates in an extremely dangerous way, regardless its original length. 


\section{Conclusions}

In this paper, we adopted a joint numerical-experimental approach to elucidate the effect different types of delaminations on the fatigue life and on the progressive damage growth. We considered three specimen types: 1) $S$, undamaged specimens, used as a reference; 2) $T$, artificially delaminated specimens at the midplane of the laminate, i.e. symmetric configuration with respect to the stacking sequence; 3) $U$, artificially delaminated specimens close to the surface, i.e. non-symmetric configuration.

Stepwise cyclic tests combined with lock-in IR-thermography allowed us to identify a damage stress, $\sigma_{\mathrm{D}}$, which corresponds to the threshold for damage initiation. If compared with the S-N curve, $\sigma_{\mathrm{D}}$ is close to the high cycle fatigue strength. The experimentally determined values of the damage stress are similar for all the tested samples, although slightly lower for the delaminated series, $\mathrm{T}$ and $\mathrm{U}$. This means that there is a threshold stress value below which the composite is not affected by the fatigue loading, even in presence of a pre-existent delamination.

Numerical FE-models of the tested specimens, created to obtain a tool useful for fatigue prediction and damage tolerant design, allowed the estimation of the S-N curve of all the specimens. The analyses also highlighted how the presence of a pre-existent delamination affects the slope of the S-N curve.

Finally, a sensitivity analysis, carried out by the previously validated models, contributed to point out the three main parameters, which play an important role on the fatigue life:

- the location of delamination, which affects the fatigue life. If the delamination is located closer to the specimen surface, the number of cycles to failure seems to decrease. This suggests that a local bending near the delaminated front, also observed during experimental testing, provides higher energy to the opening mode and accelerates the propagation;

- changes in the stacking sequence of the laminate, which result in a considerable variation in the number of cycles to failure;

- the delamination size, which has slight effect on the fatigue life.

In spite of the intrinsic limitations of the numerical models, which require a proper calibration on the specific material, the proposed methodology allows one to quantify the reduction in fatigue life of GFRP, owing to different pre-existing delaminations, and to monitor the progressive damage growth. This method could be implemented in real applications, where 
lock-in thermography could be used for in situ inspection and FE-models can represent a supportive tool for damage tolerant design.

\section{Acknowledgements}

The authors thank Prof. Gerhard Ziegmann from Technical University of Clausthal for manufacturing the tested composite.

\section{References}

[1] Wisnom MR. The role of delamination in failure of fibre-reinforced composites. Philos Trans R Soc A Math Phys Eng Sci 2012;370:1850-70. doi:10.1098/rsta.2011.0441.

[2] Reis PNB, Ferreira JAM, Antunes F V., Richardson MOW. Effect of interlayer delamination on mechanical behavior of carbon/epoxy laminates. J Compos Mater 2009;43:2609-21. doi:10.1177/0021998309344649.

[3] Zubillaga L, Turon A, Maimí P, Costa J, Mahdi S, Linde P. An energy based failure criterion for matrix crack induced delamination in laminated composite structures. Compos Struct 2014;112:339-44. doi:10.1016/j.compstruct.2014.02.015.

[4] Bak BLV, Turon A, Lindgaard E, Lund E. A benchmark study of simulation methods for high-cycle fatigue-driven delamination based on cohesive zone models. Compos Struct 2017;164:198-206. doi:10.1016/j.compstruct.2016.11.081.

[5] Karabutov AA, Podymova NB. Quantitative analysis of the influence of voids and delaminations on acoustic attenuation in CFRP composites by the laser-ultrasonic spectroscopy method. Compos Part B Eng 2014;56:238-44. doi:10.1016/j.compositesb.2013.08.040.

[6] Gholizadeh S. A review of non-destructive testing methods of composite materials. Procedia Struct Integr 2016;1:50-7. doi:10.1016/j.prostr.2016.02.008.

[7] Maldague X. Applications of infrared thermography in nondestructive evaluation. Trends Opt Non-Destructive Test Insp 2000:591-633. doi:10.1016/B978-0080430201/50040-5.

[8] Ibarra-Castanedo C, Galmiche F, Darabi A, Pilla M, Klein M, Ziadi A, et al. Thermographic nondestructive evaluation: overview of recent progress. In: Cramer KE, Maldague XP, editors. Proceeding SPIE, SPIE; 2003, p. 450. doi:10.1117/12.485699.

[9] Brémond P. New developments in Thermo Elastic Stress Analysis by Infrared Thermography. IV Conf. Panam. END, Buenos Aires: 2007. 
[10] Pitarresi G, Found MS, Patterson EA. An investigation of the influence of macroscopic heterogeneity on the thermoelastic response of fibre reinforced plastics. Compos Sci Technol 2005;65:269-80. doi:10.1016/j.compscitech.2004.07.008.

[11] Milovanović B, Banjad Pečur I. Review of Active IR Thermography for Detection and Characterization of Defects in Reinforced Concrete. J Imaging 2016;2:11. doi:10.3390/jimaging2020011.

[12] Nevadunsky JJ, Lucas JJ, Salkind MJ. Early Fatigue Damage Detection in Composite Materials. J Compos Mater 1975;9:394-408. doi:10.1177/002199837500900409.

[13] Dulieu-Barton JM. Introduction to thermoelastic stress analysis. Strain 1999;35:35-9. doi:10.1111/j.1475-1305.1999.tb01123.x.

[14] Palumbo D, De Finis R, Demelio PG, Galietti U. A new rapid thermographic method to assess the fatigue limit in GFRP composites. Compos Part B Eng 2016;103:60-7. doi:10.1016/j.compositesb.2016.08.007.

[15] Harwood N, Cummings WM. Applications of thermoelastic stress analysis. Strain 1986;22:7-12. doi:10.1111/j.1475-1305.1986.tb00014.x.

[16] Paynter RJH, Dutton AG. The use of a second harmonic correlation to detect damage in composite structures using thermoelastic stress measurements. Strain 2003;39:73-8. doi:10.1046/j.1475-1305.2003.00056.x.

[17] Colombo C, Vergani L, Burman M. Static and fatigue characterisation of new basalt fibre reinforced composites. Compos Struct 2012;94:1165-74. doi:10.1016/j.compstruct.2011.10.007.

[18] Pitarresi G, Tumino D, Mancuso A. Thermo-mechanical behaviour of flax-fibre reinforced epoxy laminates for industrial applications. Materials (Basel) 2015;8:737188. doi:10.3390/ma8115384.

[19] Colombo C, Harhash M, Palkowski H, Vergani L. Thermographic stepwise assessment of impact damage in sandwich panels. Compos Struct 2018;184:279-87. doi:10.1016/j.compstruct.2017.10.001.

[20] Saeedifar M, Fotouhi M, Ahmadi Najafabadi M, Hosseini Toudeshky H. Prediction of delamination growth in laminated composites using acoustic emission and Cohesive Zone Modeling techniques. Compos Struct 2015;124:120-7. doi:10.1016/j.compstruct.2015.01.003.

[21] Haselbach PU, Bitsche RD, Branner K. The effect of delaminations on local buckling in wind turbine blades. Renew Energy 2016;85:295-305. doi:10.1016/j.renene.2015.06.053. 
[22] Shanmugam V, Penmetsa R, Tuegel E, Clay S. Stochastic modeling of delamination growth in unidirectional composite DCB specimens using cohesive zone models. Compos Struct 2013;102:38-60. doi:10.1016/j.compstruct.2013.01.020.

[23] Camanho PP, Dávila CG. Mixed-Mode Decohesion Finite Elements for the Simulation of Delamination in Composite Materials. 2002. doi:10.1177/002199803034505.

[24] Wang $\mathrm{C}, \mathrm{Xu} \mathrm{X}$. Cohesive element analysis of fatigue delamination propagation in composite materials with improved crack tip tracking algorism. Compos Struct 2015;134:176-84. doi:10.1016/j.compstruct.2015.07.118.

[25] Jimenez S, Duddu R. On the parametric sensitivity of cohesive zone models for highcycle fatigue delamination of composites. Int J Solids Struct 2016;82:111-24. doi:10.1016/j.ijsolstr.2015.10.015.

[26] Kakei A, Epaarachchi JA, Islam M, Leng J, Rajic N. Detection and characterisation of delamination damage propagation in Woven Glass Fibre Reinforced Polymer Composite using thermoelastic response mapping. Compos Struct 2016;153:442-50. doi:10.1016/j.compstruct.2016.06.044.

[27] Colombo C, Libonati F, Vergani L. Fatigue damage in GFRP. Int J Struct Integr 2012;3:424-40. doi:10.1108/17579861211281218.

[28] Colombo C, Vergani L. Influence of delamination on fatigue properties of a fibreglass composite. Compos Struct 2014;107:325-33. doi:10.1016/j.compstruct.2013.07.028.

[29] Simpson RL. Review of Springer Handbook of Experimental Fluid Mechanics. In: Jr WNS, Sharpe WN, editors. AIAA J., vol. 46, Springer; 2008, p. 2653-5. doi:10.2514/1.38773.

[30] Sheng M, Xie J, Fu Z. Calibration-based NUC method in real-time based on IRFPA. Phys Procedia 2011;22:372-80. doi:10.1016/j.phpro.2011.11.058.

[31] Wang WJ, Dulieu-Barton JM, Li Q. Assessment of non-adiabatic behaviour in thermoelastic stress analysis of small scale components. Exp Mech 2010;50:449-61. doi:10.1007/s11340-009-9249-2.

[32] Reifsnider KL, Williams RS. Determination of Fatigue-related Heat Emission in Composite Materials during fatigue loading. Exp Mech 1974;14:479-85. doi:10.1007/BF02323148.

[33] La Rosa G, Risitano A. Thermographic methodology for rapid determination of the fatigue limit of materials and mechanical components. Int J Fatigue 2000;22:65-73. doi:10.1016/S0142-1123(99)00088-2.

[34] LAPOL/UFRGS's Composite Material and Nanocomposites Group. Mech_Gcomp n.d. 
https://gcomp-srv01.nuvem.ufrgs.br/en/ (accessed January 10, 2019).

[35] Autodesk. Helius PFA n.d. https://knowledge.autodesk.com/support/helius-pfa/ (accessed January 10, 2019).

[36] Bieniaś J, Dadej K, Surowska B. Interlaminar fracture toughness of glass and carbon reinforced multidirectional fiber metal laminates. Eng Fract Mech 2017;175:127-45. doi:10.1016/j.engfracmech.2017.02.007.

[37] Hansen AC, Garnich MR. A multicontinuum theory for structural analysis of composite material systems. Compos Eng 1995;5:1091-103. doi:10.1016/0961-9526(95)00077-Z.

[38] Montesano J, Fawaz Z, Bougherara H. Use of infrared thermography to investigate the fatigue behavior of a carbon fiber reinforced polymer composite. Compos Struct 2013;97:76-83. doi:10.1016/j.compstruct.2012.09.046. 
a)
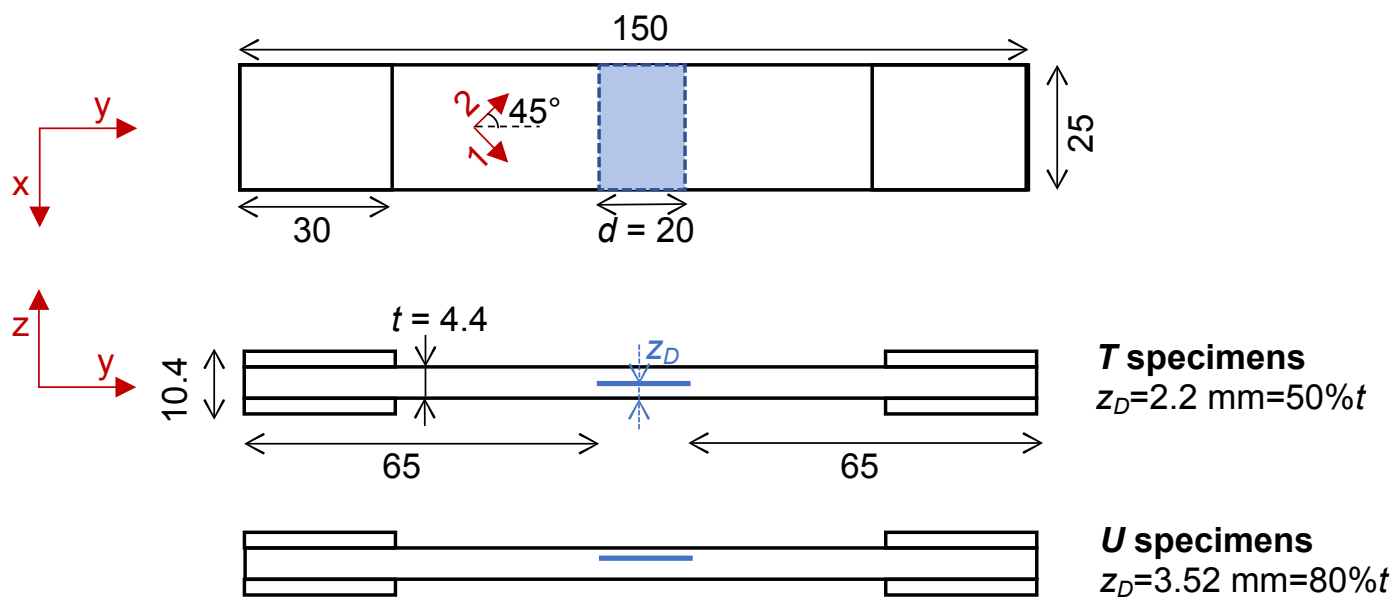

b)

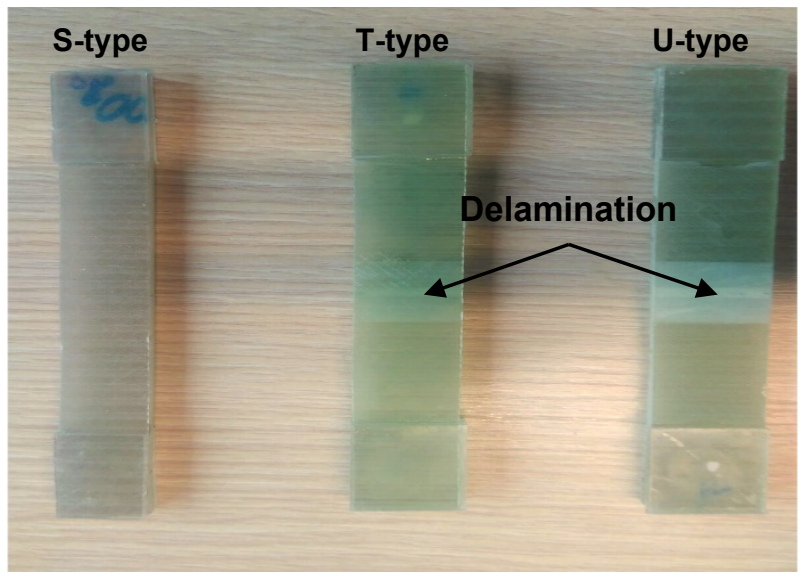

Figure 1: a) Dimensions of the delaminated specimens (mm): $t$ is the specimen thickness; $d$ is the delamination size; $z_{D}$ is the through-thickness location of the delamination, represented by means of a blue line; b) GFRP specimens: $S$-type represents the standard or undamaged specimen, $T$ type the sample with a delamination placed in the middle of the lay-up, and $U$-type the sample with delamination placed close to the upper layer. 


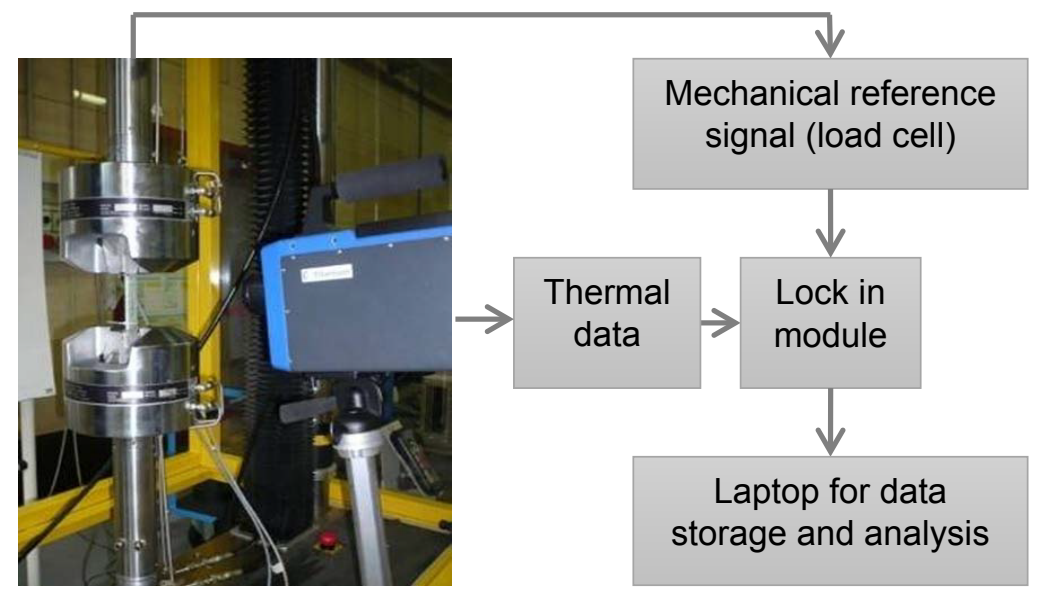

Figure 2: Scheme of the experimental setup and devices: sample placed into a universal servohydraulic testing machine and surface observed through an IR-thermal camera. 

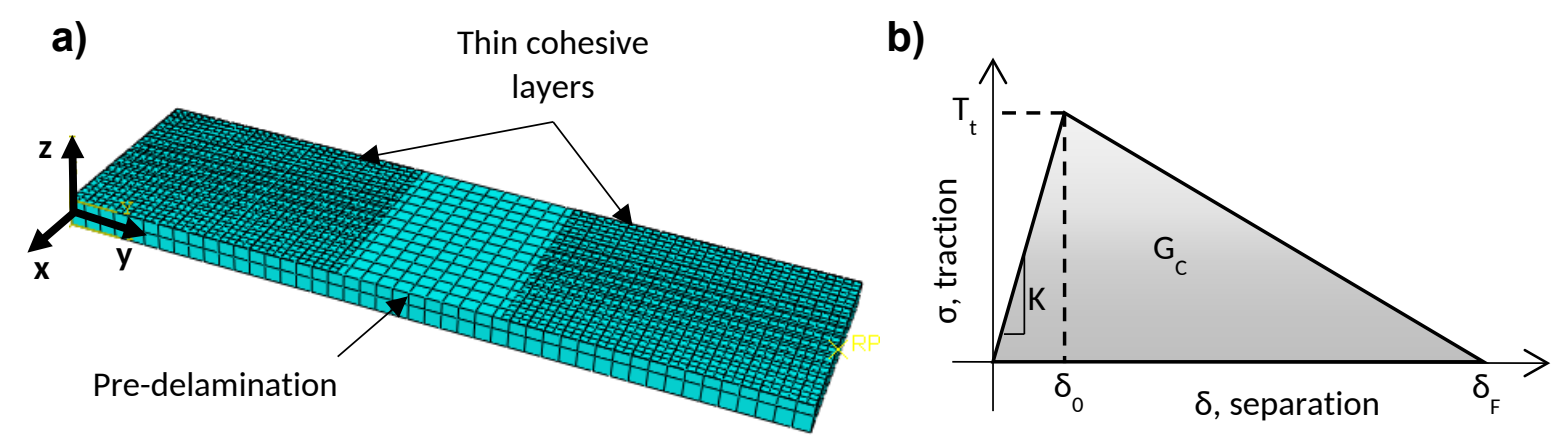

Figure 3: a) Example of mesh generated for the $T$ specimens; b) Cohesive parameters of the triangular TSL: $\mathrm{T}_{\mathrm{t}}$ maximum traction for tensile load; $\delta_{0}$ and $\delta_{\mathrm{F}}$ initial and final separation; $\mathrm{G}_{\mathrm{C}}$ fracture energy; $\mathrm{K}$ initial stiffness. 
a)

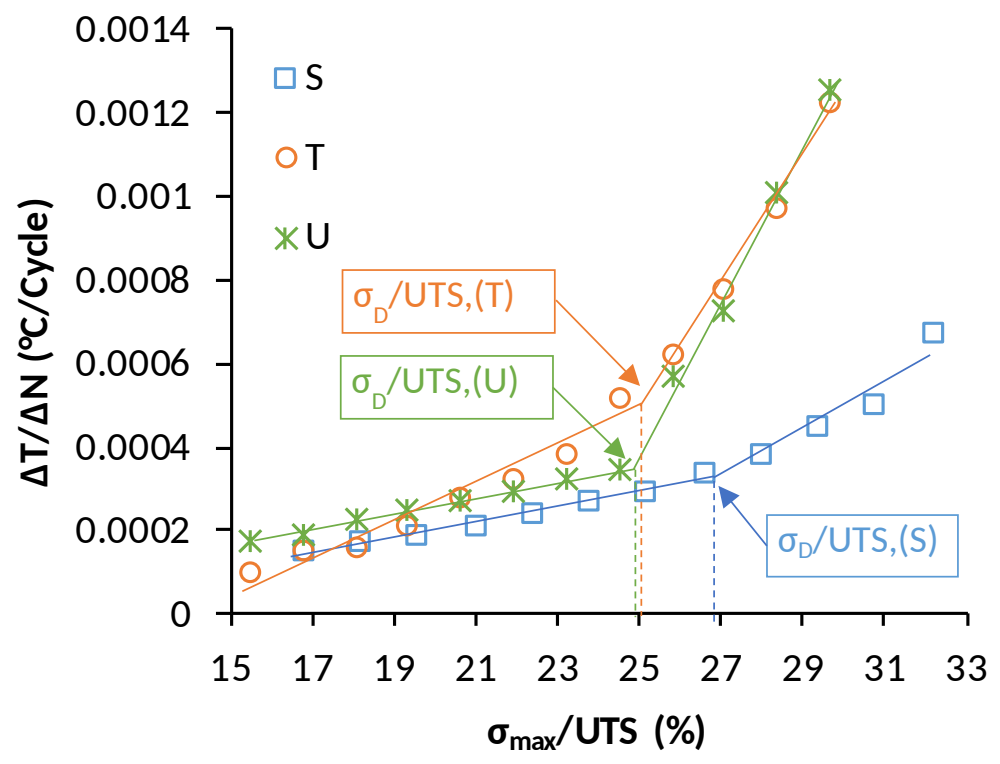

b)

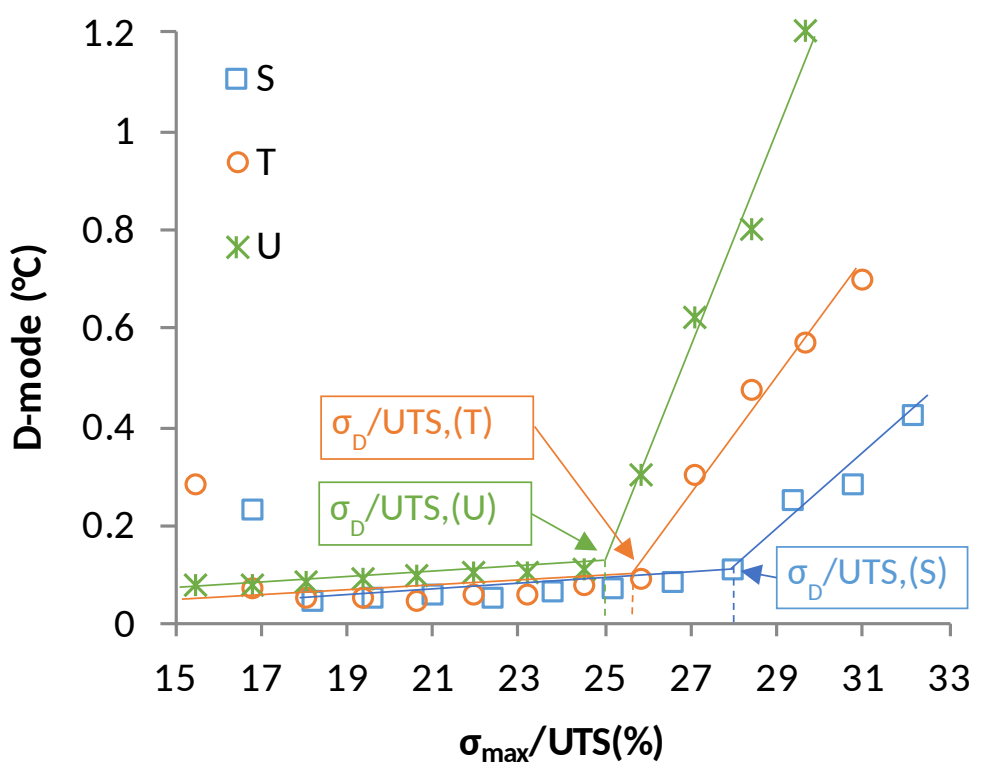


c)

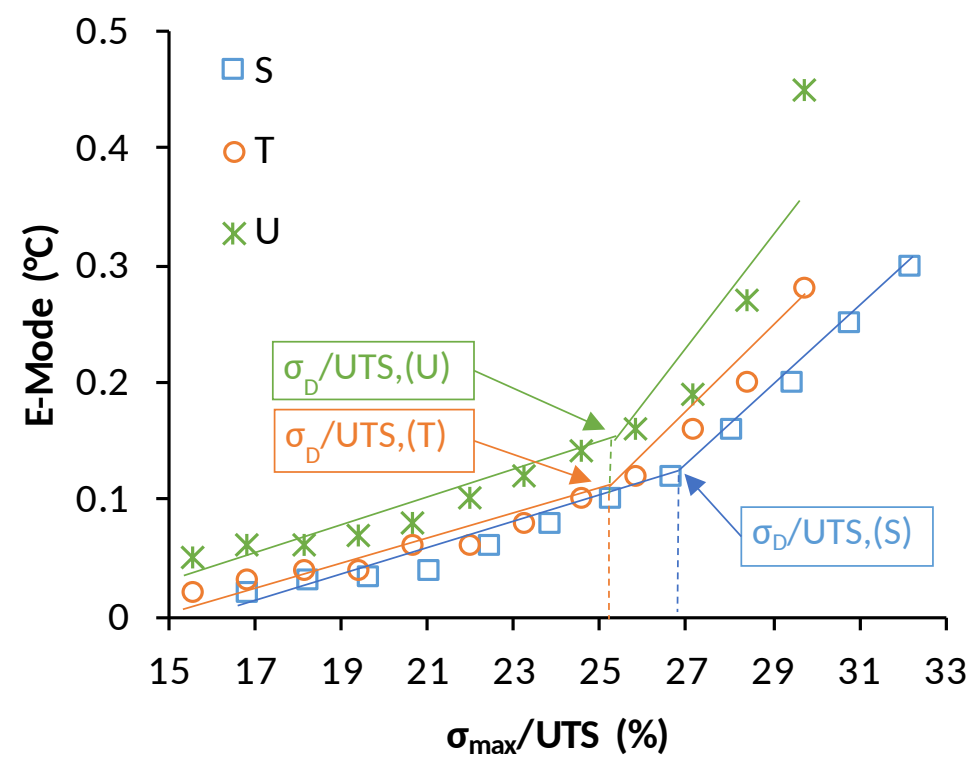

Figure 4: Curves for the thermographic determination of the damage stress $\sigma_{\mathrm{D}}$ in $S, T$ and $U$ specimens, by using three different methods: a) $\Delta \mathrm{T} / \Delta \mathrm{N}$ vs $\sigma_{\max } / \mathrm{UTS}(\%)$, b) D-mode vs $\sigma_{\max } / \mathrm{UTS}(\%)$, c) E-mode vs $\sigma_{\max } / \mathrm{UTS}(\%)$. 


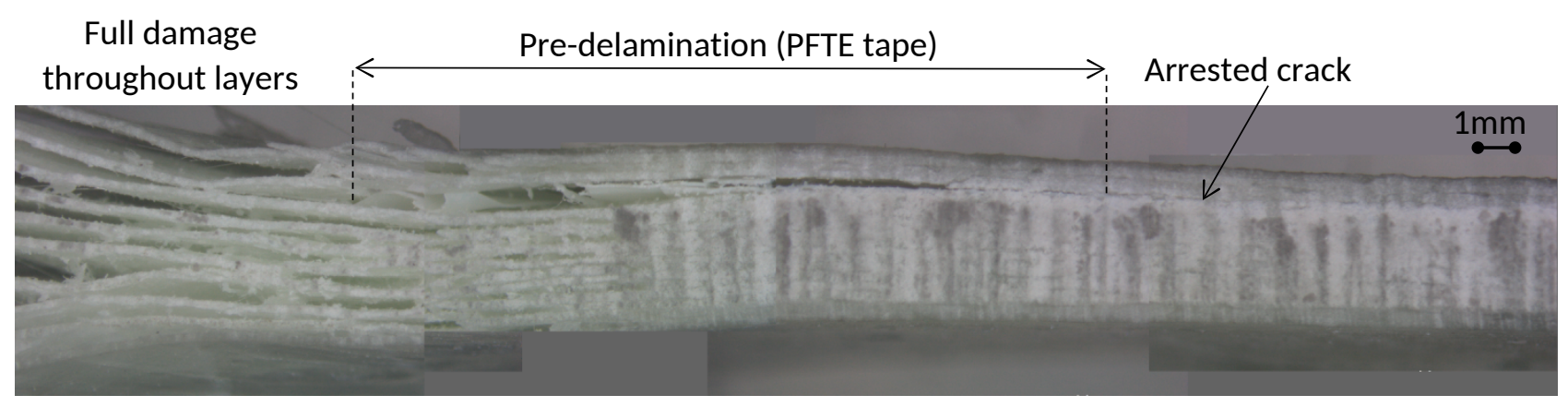

Figure 5: Failure of a U-specimen after stepwise tests. 
a)

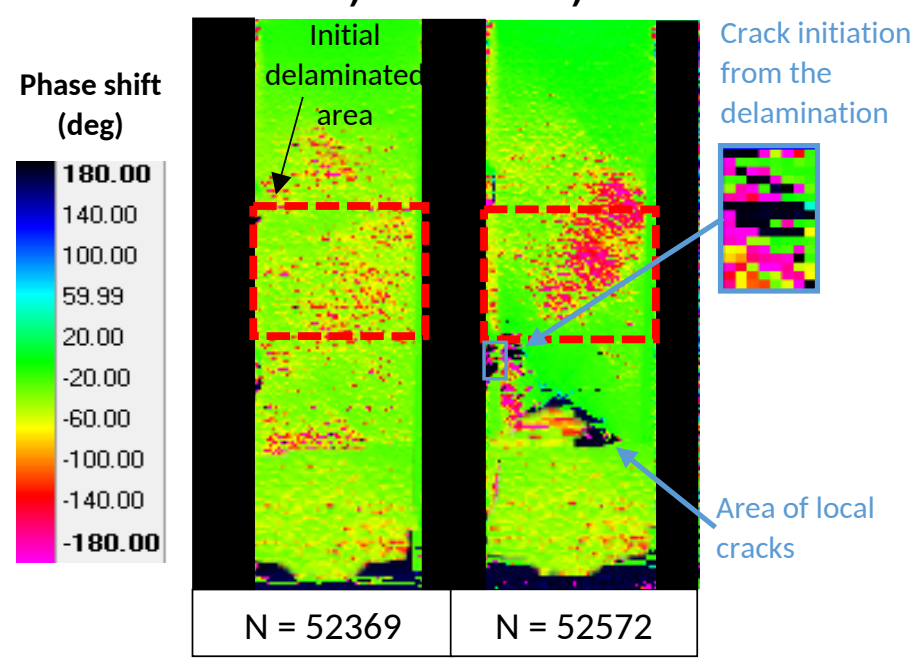

c)

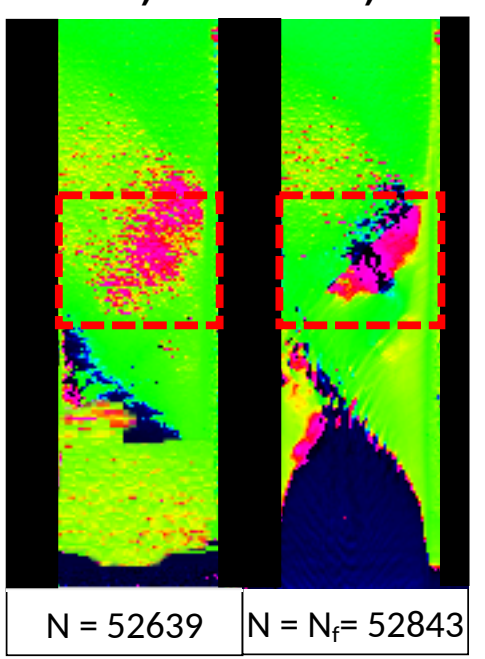

Figure 6: Phase shift of thermoelastic signal during a stepwise test of a $U$-type specimen.

Frames: a) before visible propagation of the delamination; b) damage initiation with estimation of the damage size, c) during damage propagation; d) last step of the test.

$\mathrm{N}$ is the corresponding number of cycles; $\mathrm{N}_{\mathrm{f}}$ is the number of cycles corresponding to the specimen failure. 
a)

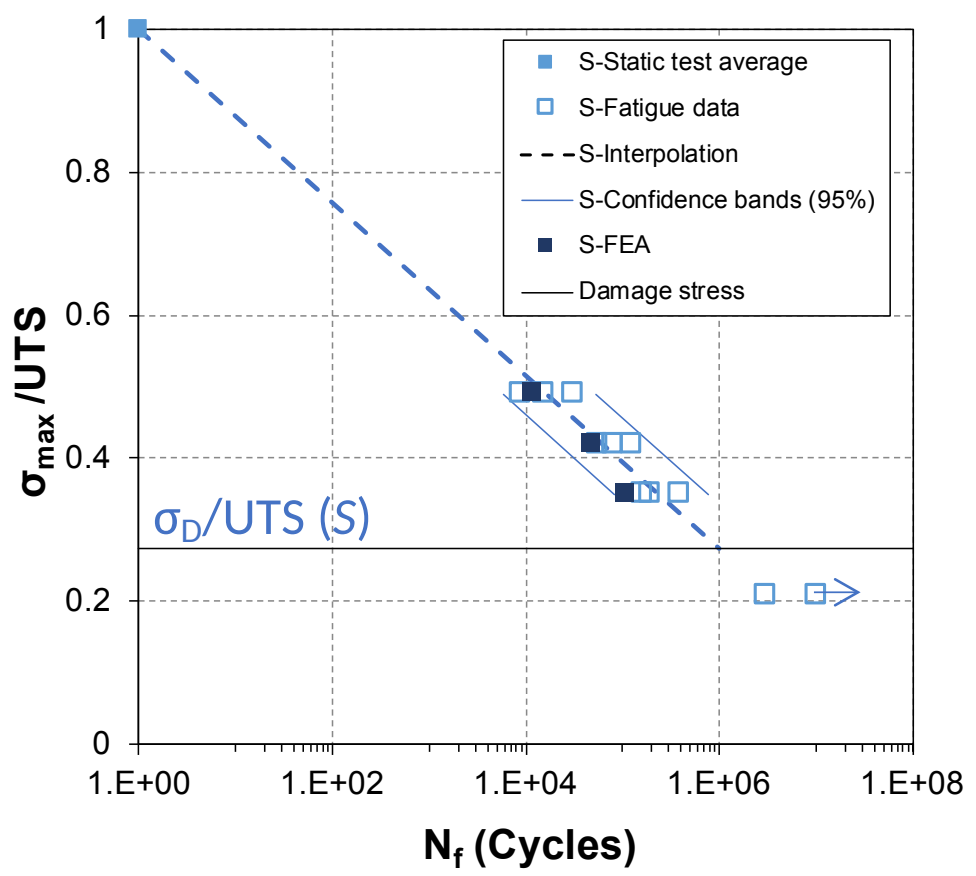

b)

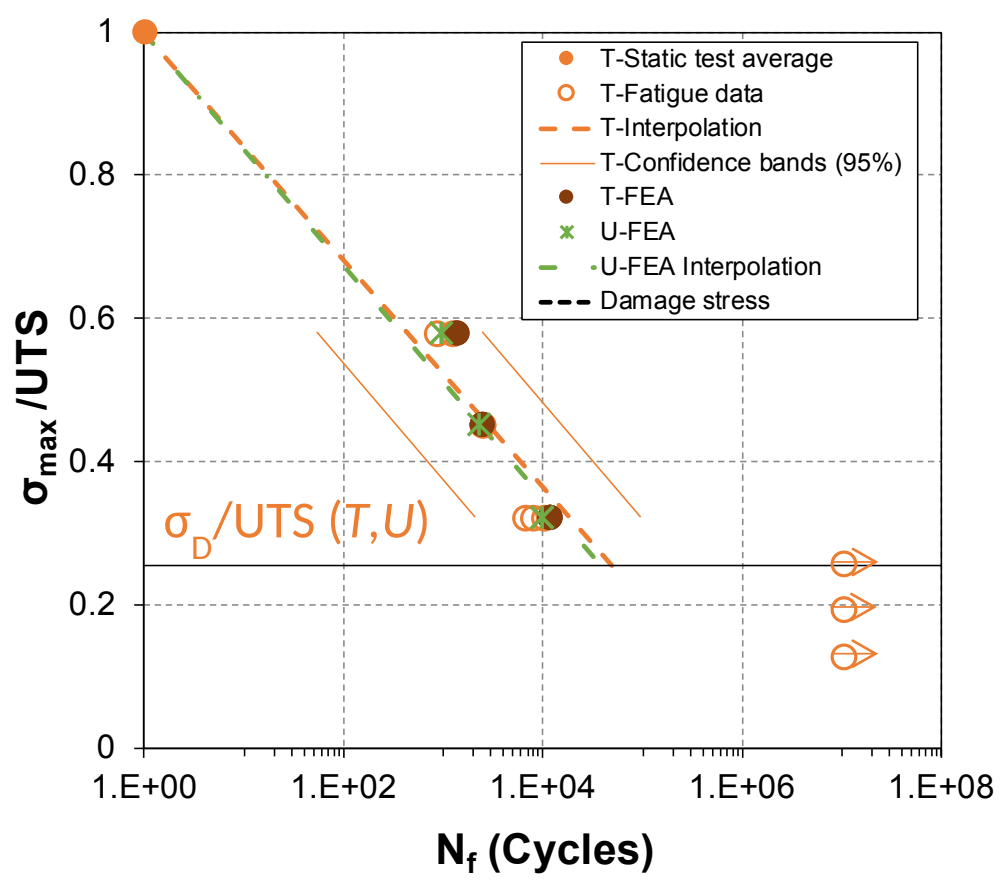

Figure 7: Comparison between numerical and experimental [28] $\sigma_{\max }$ vs $\log \left(\mathrm{N}_{\mathrm{f}}\right)$ plot or S-N curve for: a) $S$ specimens and b) $T$ and $U$ specimens. Runout specimens are identified by arrows. 


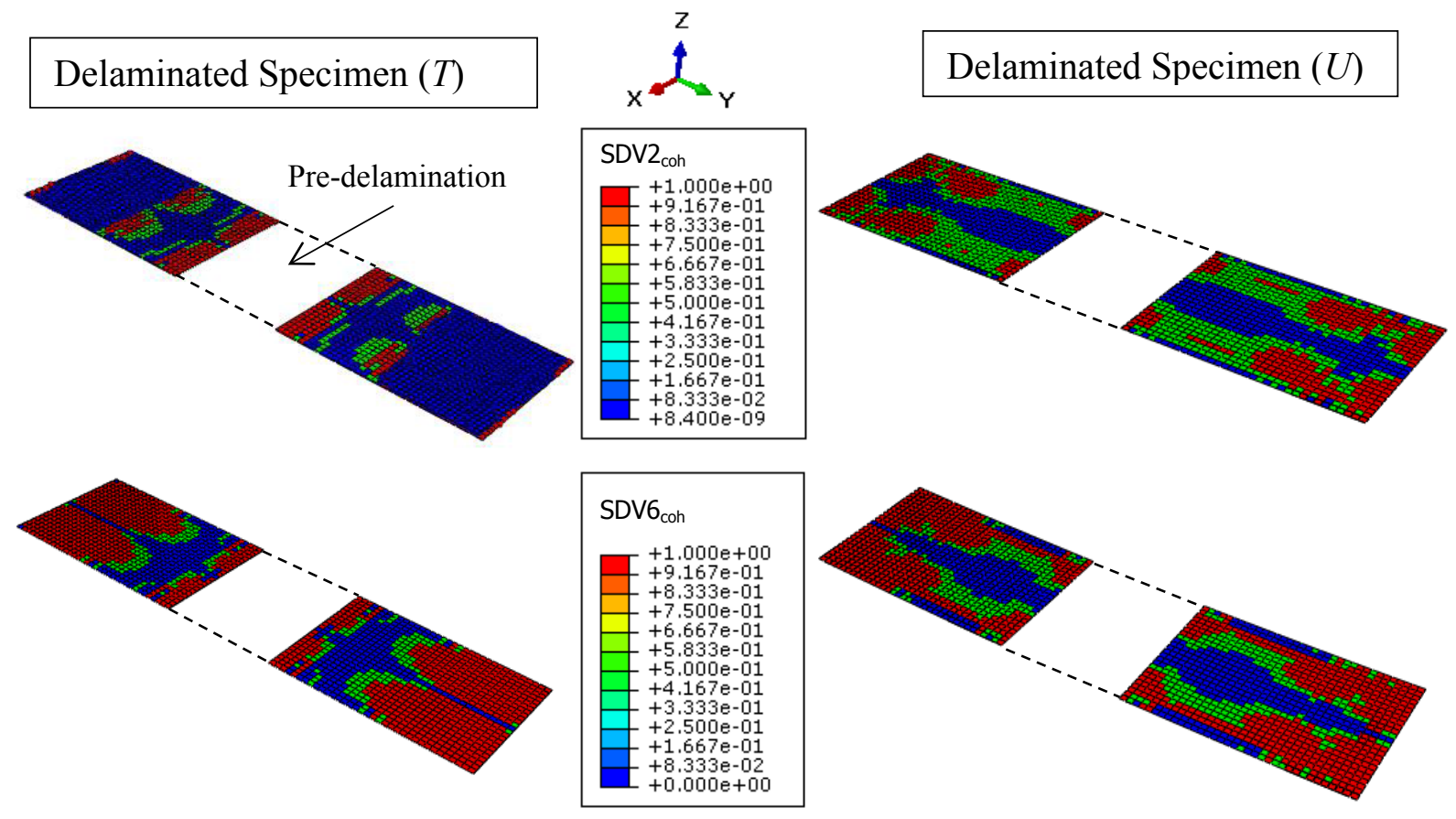

Figure 8: State defined variables $\left(\mathrm{SDV}_{\text {coh }}\right)$ into the cohesive layers of $T$ (left) and $U$ (right) specimens, at the end of the analysis. SDV2 $2_{\text {coh }}$ indicates crack initiation; SDV6 $6_{\text {coh }}$ indicates the cumulated damage. Both these $\mathrm{SDV}_{\text {coh }}$ range between 0 (no damage) and 1 (full damage). 

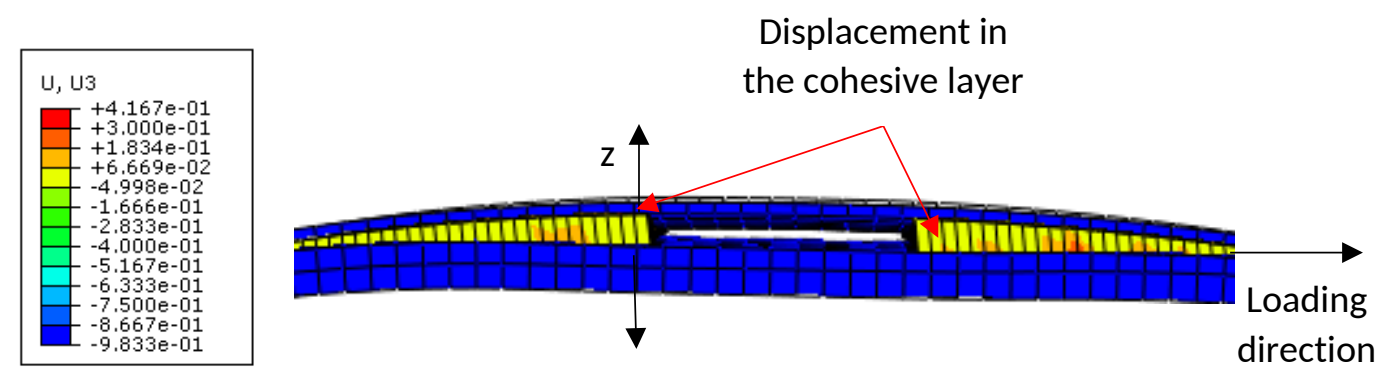

Figure 9: Displacement field U3 along the trough-thickness direction (z-axis). Values are in mm. 
a)

$$
\begin{aligned}
& \text { SDV7 } \\
& \begin{aligned}
\text { coh } \\
\begin{array}{r}
+3.469 \mathrm{e}-01 \\
+2.313 \mathrm{e}-01 \\
+1.156 \mathrm{e}-01 \\
+0.000 \mathrm{e}+00
\end{array}
\end{aligned}
\end{aligned}
$$
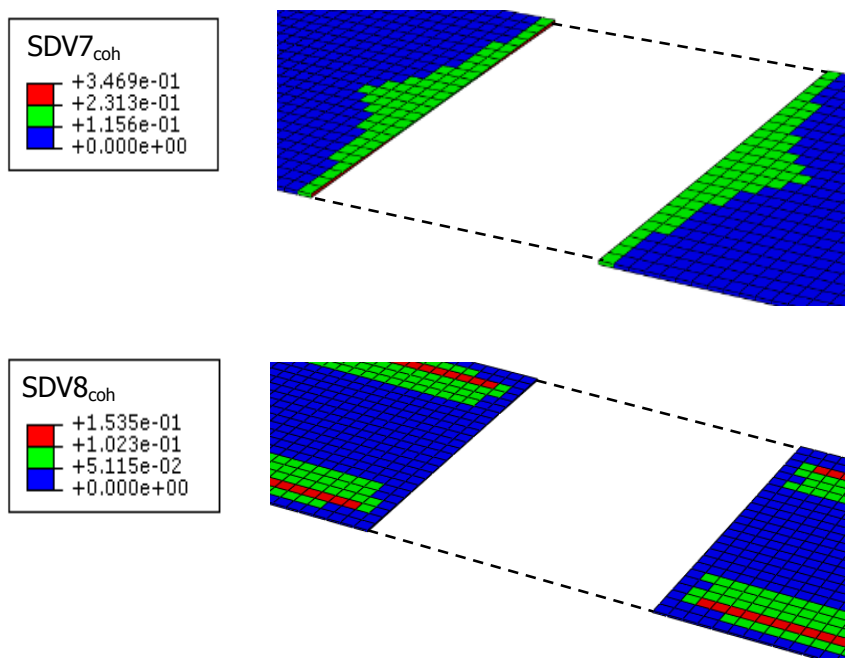

$$
\begin{aligned}
& \text { SDV9 } \\
& \begin{aligned}
\text { coh } \\
\begin{array}{r}
+1.453 \mathrm{e}-01 \\
+9.690 \mathrm{e}-02 \\
+4.845 \mathrm{e}-02 \\
+5.315 \mathrm{e}-27
\end{array}
\end{aligned}
\end{aligned}
$$

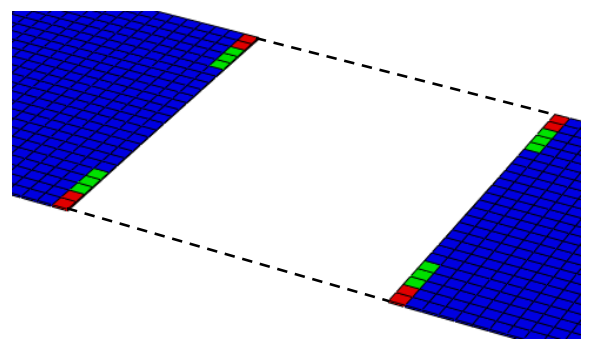


b)
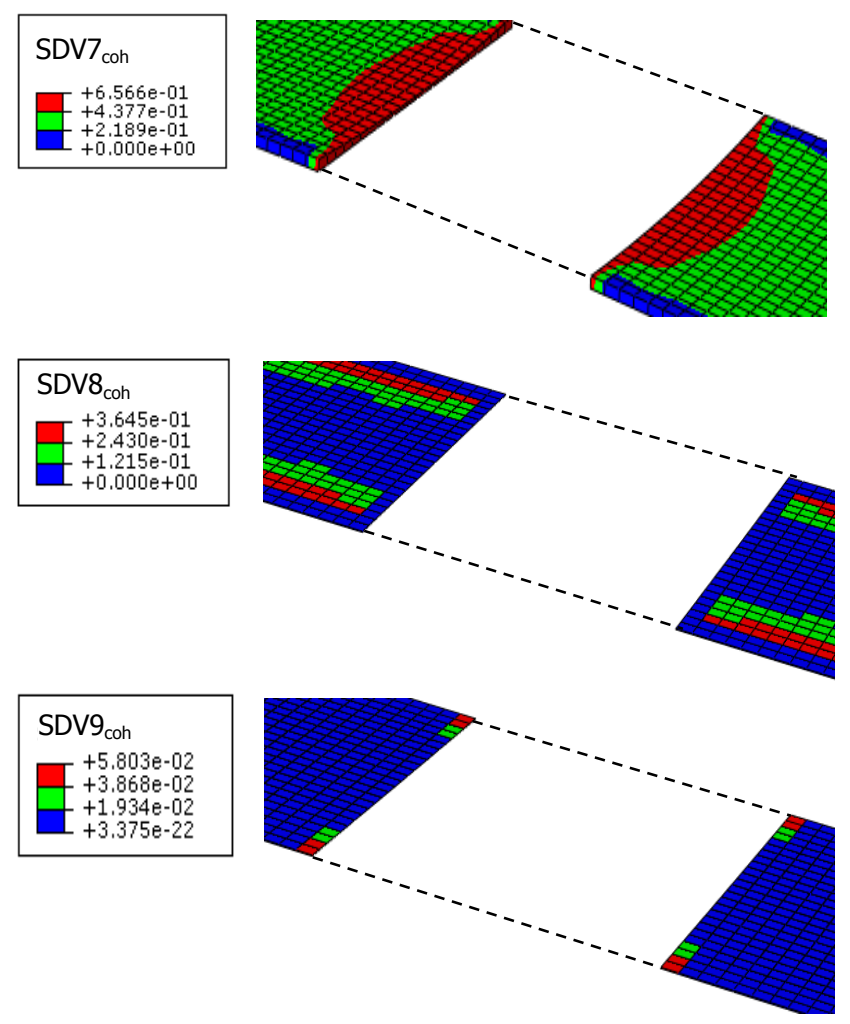

Figure 10: State defined variables $\mathrm{SDV} 7_{\text {coh }}, \mathrm{SDV} 8_{\text {coh }}, \mathrm{SDV} 9_{\text {coh }}$ give the work done in Mode I, Mode II, Mode III respectively: a) $T$ specimen b) $U$ specimen. Magnification at the delamination tips. 
Table 1: Number of experimental tests performed for each sample type. $S$ series represents the standard or undamaged specimens, $T$ series represents the samples with a delamination placed in the middle of the lay-up, and $U$ series represents the samples with a delamination placed close to the upper layer.

\begin{tabular}{cccc}
\hline Specimen ID & Static & Fatigue & Stepwise \\
\hline$S$ & 5 & 10 & 8 \\
$T$ & 3 & 11 & 3 \\
$U$ & 3 & - & 3 \\
\hline
\end{tabular}


Table 2: a) Mechanical properties of the composite lamina; 1-2 is the local in-plane reference frame of the composite lamina; axis 3 is the trough-thickness direction; b) Cohesive properties.

a)

\begin{tabular}{cc}
\hline $\begin{array}{c}\text { Mechanical properties } \\
\text { of the composite lamina }\end{array}$ \\
\hline $\mathrm{E}_{1}(\mathrm{MPa})$ & 40720 \\
$\mathrm{E}_{2}(\mathrm{MPa})$ & 40720 \\
$\mathrm{E}_{3}(\mathrm{MPa})$ & 7273 \\
$\mathrm{G}_{12}(\mathrm{MPa})$ & 6732 \\
$\mathrm{G}_{13}(\mathrm{MPa})$ & 6732 \\
$v_{12}$ & 0.252 \\
$v_{13}$ & 0.252 \\
$v_{21}$ & 0.045 \\
\hline
\end{tabular}

b)

\begin{tabular}{ccc}
\hline \multicolumn{3}{c}{ Cohesive properties } \\
\hline $\begin{array}{c}\text { Critical Energy } \\
\text { release rate } \mathrm{G}_{\mathrm{c}} \\
(\mathrm{N} / \mathrm{mm})\end{array}$ & $\begin{array}{c}\text { Traction } \\
\left(\mathrm{N} / \mathrm{mm}^{2}\right)\end{array}$ & $\begin{array}{c}\text { Stiffness } \\
\left(\mathrm{N} / \mathrm{mm}^{3}\right)\end{array}$ \\
\hline $\mathrm{G}_{\mathrm{I}}=5.479$ & $\mathrm{~T}_{\mathrm{t}}=\mathrm{T}_{\mathrm{s}}=63.64$ & $\mathrm{~K}_{\mathrm{n}}=\mathrm{K}_{\mathrm{s}}=\mathrm{K}_{\mathrm{t}}=1.66 \mathrm{E}+6$ \\
$\mathrm{G}_{\mathrm{II}}=6.364$ & $\mathrm{~T}_{\mathrm{n}}=54.79$ & \\
\hline
\end{tabular}


Table 3: Evaluation of the damage stress $\sigma_{\mathrm{D}}$ from thermal stepwise observations.

\begin{tabular}{|c|c|c|c|c|c|}
\hline $\begin{array}{l}\text { Specimen } \\
\text { ID }\end{array}$ & $\begin{array}{c}\sigma_{\mathrm{D}}(\mathrm{MPa}) \text { from } \\
\Delta \mathrm{T} / \Delta \mathrm{N} \text { vs } \sigma_{\max } \\
(\% \mathrm{UTS})\end{array}$ & $\begin{array}{c}\sigma_{\mathrm{D}}(\mathrm{MPa}) \text { from } \\
\text { D-Mode } \\
(\% \text { UTS })\end{array}$ & $\begin{array}{c}\sigma_{D}(M P a) \\
\text { from E-Mode } \\
(\% \text { UTS })\end{array}$ & $\begin{array}{c}\text { Average } \\
\sigma_{\mathrm{D}}(\mathrm{MPa})\end{array}$ & $\begin{array}{c}\text { Difference } \\
(\%)\end{array}$ \\
\hline$S$ & $27.0 \pm 1.0$ & $28.0 \pm 0.8$ & $27.1 \pm 1.8$ & $27.4 \pm 1.2$ & - \\
\hline$T$ & $25.7 \pm 0.3$ & $25.7 \pm 0.7$ & $25.5 \pm 0.5$ & $25.6 \pm 0.5$ & $-6.5 \%$ \\
\hline$U$ & $25.2 \pm 0.5$ & $25.9 \pm 0.2$ & $25.5 \pm 0.7$ & $25.5 \pm 0.5$ & $-7.2 \%$ \\
\hline
\end{tabular}


Table 4: Number of cycles to failure $\mathrm{N}_{\mathrm{f}}$, numerically estimated from $\mathrm{SDV} 2_{\text {coh }}$, for different positions of the delamination, stacking sequence and size of the delamination.

\begin{tabular}{|c|c|c|c|c|}
\hline & & \multirow{2}{*}{\multicolumn{3}{|c|}{ Applied Stress $\sigma_{\max }(\mathrm{MPa})$}} \\
\hline & & & & \\
\hline & & 50 & 70 & 90 \\
\hline \multirow{5}{*}{$\begin{array}{c}\text { Position } \\
\text { of the } \\
\text { delamination }\end{array}$} & $z_{D}=2.20 \mathrm{~mm}=50 \% \cdot t$ & $1.35 \mathrm{E}+03$ & $2.47 \mathrm{E}+03$ & $1.15 \mathrm{E}+04$ \\
\hline & $z_{D}=2.64 \mathrm{~mm}=60 \% \cdot t$ & $1.21 \mathrm{E}+03$ & $2.41 \mathrm{E}+03$ & $1.09 \mathrm{E}+04$ \\
\hline & $z_{D}=3.08 \mathrm{~mm}=70 \% \cdot t$ & $1.08 \mathrm{E}+03$ & $2.36 \mathrm{E}+03$ & $1.03 \mathrm{E}+04$ \\
\hline & $z_{D}=3.52 \mathrm{~mm}=80 \% \cdot t$ & $9.47 \mathrm{E}+02$ & $2.29 \mathrm{E}+03$ & $9.68 \mathrm{E}+03$ \\
\hline & $z_{D}=3.96 \mathrm{~mm}=90 \% \cdot t$ & $8.24 \mathrm{E}+02$ & $2.22 \mathrm{E}+03$ & $9.18 \mathrm{E}+03$ \\
\hline \multirow{3}{*}{$\begin{array}{l}\text { Stacking } \\
\text { sequence }\end{array}$} & {$[ \pm 45]$} & $1.35 \mathrm{E}+03$ & $2.47 \mathrm{E}+03$ & $3.96 \mathrm{E}+03$ \\
\hline & {$[0,90]$} & $1.81 \mathrm{E}+03$ & $1.15 \mathrm{E}+04$ & $2.01 \mathrm{E}+04$ \\
\hline & {$[0,0,0, \pm 45,0]$} & Runout & Runout & Runout \\
\hline Size & $d=10 \mathrm{~mm}$ & $1.40 \mathrm{E}+03$ & $2.52 \mathrm{E}+03$ & $1.18 \mathrm{E}+04$ \\
\hline of the & $d=20 \mathrm{~mm}$ & $1.35 \mathrm{E}+03$ & $2.47 \mathrm{E}+03$ & $1.15 \mathrm{E}+04$ \\
\hline delamination & $d=30 \mathrm{~mm}$ & $1.32 \mathrm{E}+03$ & $2.37 \mathrm{E}+03$ & $1.13 \mathrm{E}+04$ \\
\hline
\end{tabular}

